\title{
Density, proportion, and dendritic coverage of retinal ganglion cells of the common marmoset (Callithrix jacchus jacchus)
}

F.L. Gomes, L.C.L. Silveira, C.A. Saito and E.S. Yamada
Departamento de Fisiologia, Universidade Federal do Pará, Belém, PA, Brasil

\section{Correspondence \\ L.C.L. Silveira \\ Departamento de Fisiologia \\ Centro de Ciências Biológicas, UFPA \\ 66075-110 Belém, PA \\ Brasil \\ E-mail: luiz@ufpa.br}

Research supported by FINEP/FADESP (No. 66.94.0034.00), PRONEX/FUJB (No. 76.97.1028.00), CNPq (No. 521640/96-2), and UFPa-PROPESP (No. 20062/93). F.L. Gomes and C.A. Saito were recipients of CAPES fellowships for graduate students. L.C.L. Silveira and E.S. Yamada are recipients of $\mathrm{CNPq}$ research fellowships.

Received May 27, 2004 Accepted February 21, 2005

\begin{abstract}
We performed a quantitative analysis of $\mathrm{M}$ and $\mathrm{P}$ cell mosaics of the common-marmoset retina. Ganglion cells were labeled retrogradely from optic nerve deposits of Biocytin. The labeling was visualized using horseradish peroxidase (HRP) histochemistry and 3-3'diaminobenzidine as chromogen. $\mathrm{M}$ and $\mathrm{P}$ cells were morphologically similar to those found in Old- and New-World primates. Measurements were performed on well-stained cells from 4 retinas of different animals. We analyzed separate mosaics for inner and outer $\mathrm{M}$ and $\mathrm{P}$ cells at increasing distances from the fovea $(2.5-9 \mathrm{~mm}$ of eccentricity) to estimate cell density, proportion, and dendritic coverage. M cell density decreased towards the retinal periphery in all quadrants. M cell density was higher in the nasal quadrant than in other retinal regions at similar eccentricities, reaching about 740 cells $/ \mathrm{mm}^{2}$ at $2.5 \mathrm{~mm}$ of temporal eccentricity, and representing $8-14 \%$ of all ganglion cells. $\mathrm{P}$ cell density increased from peripheral to more central regions, reaching about 5540 cells $/ \mathrm{mm}^{2}$ at $2.5 \mathrm{~mm}$ of temporal eccentricity. P cells represented a smaller proportion of all ganglion cells in the nasal quadrant than in other quadrants, and their numbers increased towards central retinal regions. The $\mathrm{M}$ cell coverage factor ranged from 5 to 12 and the $\mathrm{P}$ cell coverage factor ranged from 1 to 3 in the nasal quadrant and from 5 to 12 in the other quadrants. These results show that central and peripheral retinal regions differ in terms of cell class proportions and dendritic coverage, and their properties do not result from simply scaling down cell density. Therefore, differences in functional properties between central and peripheral vision should take these distinct regional retinal characteristics into account.
\end{abstract}

\section{Introduction}

In order to understand how the image is sampled at the earliest stages of visual information processing, it is important to know how different ganglion cell classes are distributed throughout the retina. Although
Key words

- Magnocellular pathway

- Parvocellular pathway

- Visual system

- Parallel processing

- New World primates 
cells, respectively), or considered how the $\mathrm{P} /$ $\mathrm{M}$ density ratio varies throughout the retina. There are indications that the $\mathrm{P} / \mathrm{M}$ density ratio remains fairly constant in the central retina, but changes towards the nasal periphery (4-7). In addition, we also know that in some species $\mathrm{M}$ cells represent 5 to $10 \%$ of all ganglion cells in the central retina, but that this proportion increases towards the nasal periphery $(8,9)$.

Another important measurement for morphologic studies of the retina is the coverage factor, which was introduced by Perry and colleagues (4) to quantify how many cells of a single type cover each retinal location. There are controversial reports about how the $\mathrm{M}$ and $\mathrm{P}$ cell coverage factor is correlated with retinal eccentricity. Dacey and Petersen (5) and Dacey (6) suggested that the coverage factor remains constant with eccentricity in the human and macaque retina because the increase of the dendritic field size is counterbalanced by a proportional decrease of cell density. On the other hand, Perry et al. (4) for the macaque monkey retina and Yamada et al. (7) for the capuchin monkey retina, showed that the $\mathrm{M}$ and $\mathrm{P}$ cell coverage factor changes as a function of eccentricity.

In the present study, we estimated the dendritic field size, cell body size, cell density, and coverage factor for marmoset $\mathrm{M}$ and $\mathrm{P}$ cells at several different retinal eccentricities. We also estimated the proportion of $\mathrm{M}$ and $\mathrm{P}$ cells among the total ganglion cell population, as well as the $\mathrm{P} / \mathrm{M}$ density ratio at different retinal eccentricities. Some of the results were presented at the Association for Research in Vision and Ophthalmology (ARVO) Annual Meeting (10).

\section{Material and Methods}

\section{Animals}

Four adult male common marmosets Callithrix jacchus jacchus were used. The animals were bred in the Centro Nacional de Primatas (Ananindeua, State of Pará, Brazil). Animal care, anesthesia, and surgery were in agreement with the recommendations of ARVO.

\section{Surgery}

Retinal ganglion cells were labeled according to the protocol of Picanço-Diniz et al. (11). The animal was anesthetized with ketamine hydrochloride (Ketalar, $10 \mathrm{mg} / \mathrm{ml}$; Parke-Davis, Guarulhos, SP, Brazil) and xylazine (Rompun, $20 \mathrm{mg} / \mathrm{ml}$; Bayer, São Paulo, SP, Brazil), im, and then positioned in a head holder. A craniotomy was performed and orbit bone was removed until the optic foramina became visible. Retrobulbar orbital tissue was dissected to expose the optic nerve. A few pellets of biotinyl-lysine (Biocytin; Sigma, St. Louis, MO, USA) crystallized in a surgical sponge were placed in a cross-shaped cut made in the optic nerve at 1-3 mm behind the eyeball. The wound was covered with plastic and sealed with surgical glue. Electrocardiogram and body temperature were monitored throughout the experiment. After surgery, the animal was allowed to recover from anesthesia, and was given antibiotics and analgesics until the time for perfusion.

\section{Perfusion, retinal dissection, and histochemistry}

After a 48-h survival time, the animal was euthanized with a lethal dose of barbiturate (Thionembutal; Abbott, São Paulo, SP, Brazil), $150 \mathrm{mg} / \mathrm{kg}$, and perfused transaortically with phosphate-buffered saline (PBS) followed by $4 \%$ paraformaldehyde (PFA). The eye was removed and the retina was carefully dissected in 4\% PFA. The retina was immersed in $0.01 \%(\mathrm{w} / \mathrm{v})$ collagenase solution (collagenase from Clostridium histolyticum; Boehringer Mannheim, Germany) for 5-15 min. This procedure was 
used to break the collagen fibers in the inner limiting membrane and improve reagent penetration. The vitreous body was fully removed.

Labeled cells were visualized by a modification of the protocol of Shu et al. (12). The retina was washed in PBS, immersed in $\mathrm{ABC}$ solution (Vectastain ABC Kit Standard; Vector Laboratories, Burlingame, CA, USA) for $24-48 \mathrm{~h}$, at $4^{\circ} \mathrm{C}$, under constant agitation, washed again in $0.1 \mathrm{M}$ acetate buffer, $\mathrm{pH}$ 6.0 , for $30 \mathrm{~min}$, and then incubated in a 3 3 'diaminobenzidine (DAB) solution (Sigma) containing nickel ammonium sulfate, ammonium chloride, and $\beta$-D-glucose for 15 min. Finally, glucose oxidase (Sigma) was added to the solution, releasing $\mathrm{H}_{2} \mathrm{O}_{2}$ to allow DAB oxidization by horseradish peroxidase. The reaction yielded a dark blue precipitate which allowed visualization of labeled cells. Labeling was intensified by immersing the retina in a $0.1 \%$-osmium tetroxide solution for $1 \mathrm{~min}$.

\section{Analysis}

Microscopic analysis was performed using a 100X-oil immersion objective. Welllabeled retinal ganglion cells located at different distances from the fovea were selected for analysis. The quality of labeling was judged by how well the high-order dendritic branches were developed. Retinal shrinkage was estimated using drawings of retinal contours made before and after histology and by comparing the distance between the fovea and the optic nerve head. We corrected for shrinkage when the distance measured after histology was smaller than one standard deviation compared to the mean value of all studied retinas before histology. For each ganglion cell, $\mathrm{M}$ or $\mathrm{P}$, we traced the cell body and dendritic field contours and determined the level of dendritic field stratification in the inner plexiform layer by observing the plane of focus during microscopic observation. Using this procedure
$\mathrm{M}$ and $\mathrm{P}$ cells were classified into outer and inner varieties depending on whether they had dendrites branching in the sublayer "a" or " $b$ " of the inner plexiform layer, respectively. The cell body and dendritic field areas were estimated using a bit pad coupled to an IBM-personal compatible computer. The dendritic field areas were measured using the smallest convex polygon enclosing the full profile. Cell body or dendritic field diameter was expressed as the diameter of a circle with the same area.

Mosaics of inner and outer varieties of $\mathrm{M}$ and $\mathrm{P}$ cells were drawn from selected regions at different distances from the fovea ranging from 2-8 $\mathrm{mm}$, and the Cartesian coordinates of each cell body were digitized.

In order to analyze each subpopulation of the ganglion cell mosaic we developed software based on the algorithm of Rodieck (13). The analysis was performed using a spatial autocorrelogram of 15 concentric rings of the same width, ring width corresponding to cell body radius at that eccentricity. The mosaic was divided into a central zone where the analysis was performed surrounded by a buffer zone whose width corresponded to the autocorrelogram radius. The effective radius, a measure of the tendency of one cell type to avoid another cell of the same type on the plane of the retina, was estimated and its value was used to draw a circle around each labeled cell in the mosaic. New cells were then interpolated among the labeled cells, being placed in the void spaces near the labeled cells, outside the zone defined by the effective radius. For the mosaic encompassing labeled and interpolated cells, a new autocorrelogram was calculated, and the whole process repeated. For most mosaics, one or two interactions were necessary to fill the analyzed zone of the mosaic. Finally, cell density was obtained by direct counting of labeled and interpolated cells present in the analysis zone. Mosaic regularity was estimated by its regularity index (14) and packing factor (13). 
Figure 1. Photomicrographs of marmoset $\mathrm{M}$ and $\mathrm{P}$ ganglion cells labeled from Biocytin deposits in the optic nerve. Focus is on the dendritic field at the level of the inner plexiform layer. $A$, Outer $\mathrm{M}$ cell at $0.45 \mathrm{~mm}$ temporal to the fovea. $B$, Outer $\mathrm{P}$ cell at $0.45 \mathrm{~mm}$ temporal to the fovea. $C$, Outer M cell $1.95 \mathrm{~mm}$ temporal to the fovea. $D$, Outer $P$ cell $1.85 \mathrm{~mm}$ temporal to the fovea. E, Outer $M$ cell $4 \mathrm{~mm}$ $\mathrm{P}$ cell $3 \mathrm{~mm}$ temporal to the fovea. Scale bars $=10 \mu \mathrm{m}$ for A, B; $20 \mu \mathrm{m}$ for $C, D ; 30 \mu \mathrm{m}$ for E, $F$. temporal to the fovea. F, Outer
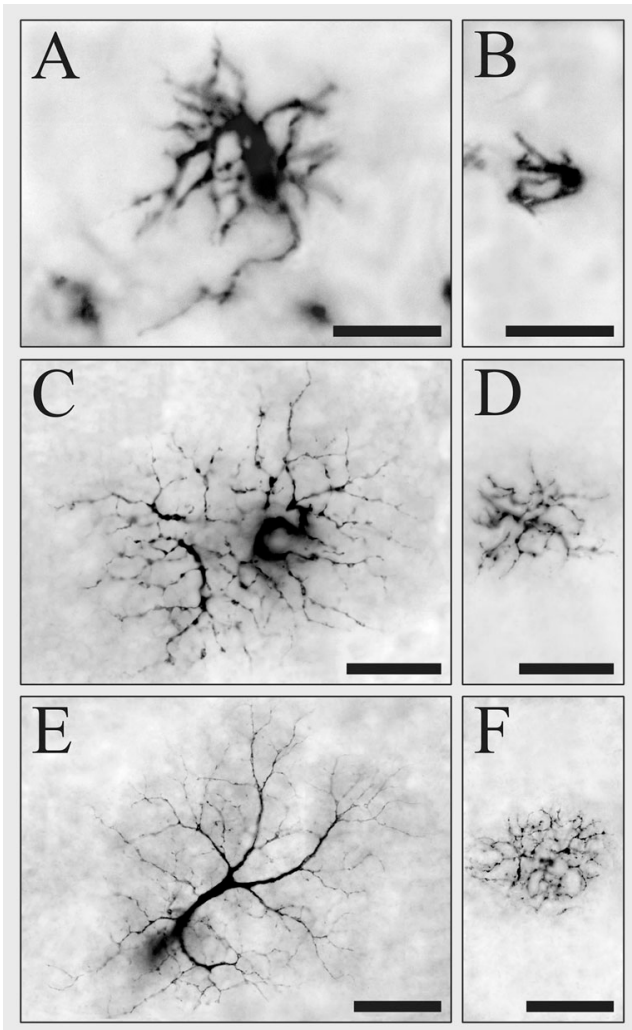

Figure 2. Dendritic field size of marmoset $\mathrm{M}$ and $\mathrm{P}$ ganglion cells as a function of eccentricity. $A$, Dendritic field size in the temporal, dorsal, and ventral quadrants. $B$, Dendritic field size in the nasal quadrant. The curves are best-fitted fourth-order polynomials and were obtained by the least square method. The insets represent the ratio for $\mathrm{M} / \mathrm{P}$ dendritic field sizes as a function of eccentricity, which was obtained by dividing the best-fitted polynomials. $M$ dendritic fields are about three times larger than $\mathrm{P}$ dendritic fields throughout most of the retina. Open squares: outer $M$ cells; filled squares: inner $M$ cells; open circles: outer P cells; filled circles: inner $P$ cells.
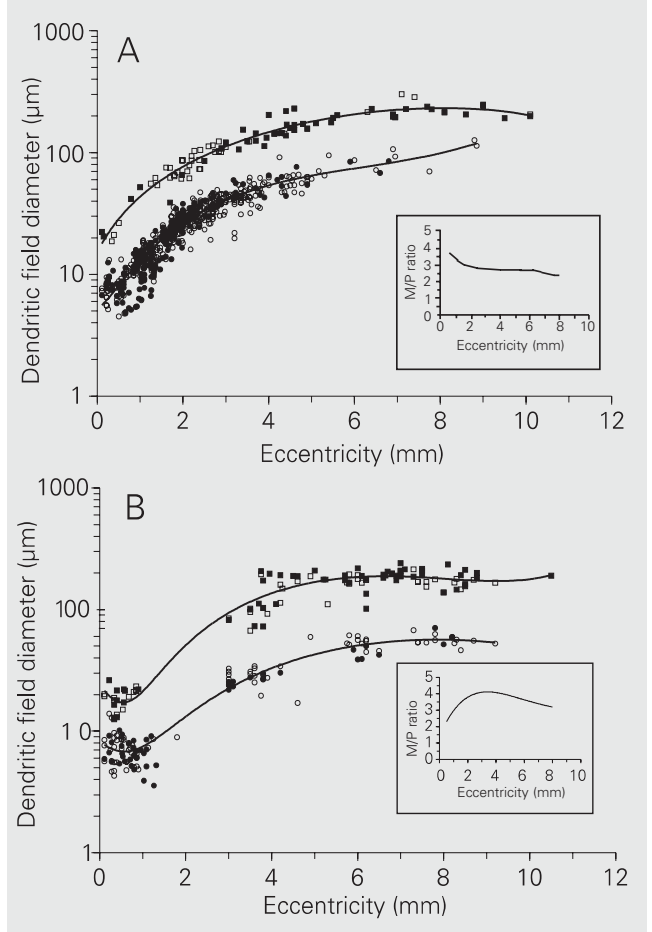

\section{Results}

\section{Morphology of $M$ and $P$ cells of the marmoset retina}

Cell morphology was quantified by measuring a sample of $182 \mathrm{M}$ cells and $839 \mathrm{P}$ cells. Marmoset $\mathrm{M}$ and $\mathrm{P}$ cells were classified according to criteria previously established for New World anthropoids (15-17). Figure 1 shows examples of $\mathrm{M}$ and $\mathrm{P}$ ganglion cells labeled retrogradely with Biocytin at different eccentricities in a marmoset retina. It can be observed that Biocytin provided complete filling of cell body, dendrites (even the finest ones) and axon. Morphologically, marmoset $\mathrm{M}$ and $\mathrm{P}$ cells were similar to those described in Old and New World anthropoids. No differences were observed in the shape and size of cell bodies and dendritic fields of the inner and outer varieties of $\mathrm{M}$ and $\mathrm{P}$ cells. Marmoset $\mathrm{P}$ cells located in the central retinal region had the characteristic morphology of midget ganglion cells described by Polyak (18).

\section{Dendrite and cell body sizes of $M$ and $P$ cells}

Figures 2 and 3 show how $\mathrm{M}$ and $\mathrm{P}$ dendritic field and cell body sizes vary as a function of eccentricity in the marmoset retina. Numerical values for representative regions are listed in Table 1. Because of known anisotropies in ganglion-cell density (e.g., 1), data are shown separately for the nasal quadrant (Figures 2B and 3B) and for the combined temporal, dorsal, and ventral quadrants (Figures 2A and 3A). For convenience, the latter will be termed TDV quadrants. $M$ cell dendritic fields were significantly larger than those of $\mathrm{P}$ cells, about 2-4 times at most retinal locations (two-tailed Student $t$-test, $\mathrm{P}<0.01$; see insets in Figure 2A,B). Only small differences in cell body size were found between $\mathrm{M}$ and $\mathrm{P}$ cells. These differences were not larger than 1.6 times, and were statistically significant for 
eccentricities larger than $3 \mathrm{~mm}$ from fovea $(\mathrm{P}<0.01$; see insets in Figure 3A,B).

\section{Density of $M$ and $P$ cells}

Cell density was estimated in 24 mosaics: 12 mosaics from the nasal quadrant and 12 mosaics from the TDV quadrants (Table 2). Examples of such mosaics are shown in Figures 4 and 5. The cell body contour and primary dendrites of each cell in the mosaic were drawn.

We estimated cell density for outer and inner varieties of $\mathrm{M}$ and $\mathrm{P}$ cells from their mosaics using the spatial statistic routine de-
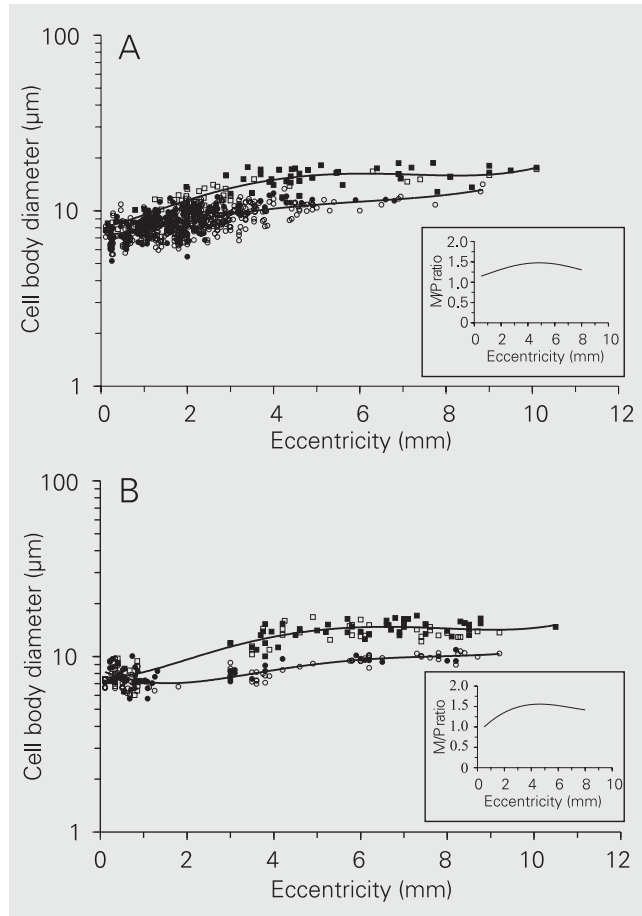

Figure 3. Cell body size of marmoset $\mathrm{M}$ and $\mathrm{P}$ ganglion cells as a function of eccentricity. $A$, Cell body size in the temporal, dorsal, and ventral (TDV) quadrants. $B$, Cell body size in the nasal quadrant. The curves are best-fitted fourth-order polynomials and were obtained by the least square method. The insets represent the ratio for M/P cell body sizes as a function of eccentricity, which was obtained by dividing the best-fitted polynomials. $M$ cell bodies are about 1.5 times larger than $P$ cell bodies throughout most of the retina. Open squares: outer $M$ cells; filled squares: inner $M$ cells; open circles: outer $\mathrm{P}$ cells; filled circles: inner $\mathrm{P}$ cells.
Table 1. Dendritic field and cell body size for $\mathrm{M}$ and $\mathrm{P}$ cells of the marmoset retina.

\begin{tabular}{lccccr}
\hline Cell class & Location & $\begin{array}{c}\text { Eccentricity } \\
(\mathrm{mm})\end{array}$ & $\begin{array}{c}\text { Dendritic field } \\
\text { diameter }(\mu \mathrm{m})\end{array}$ & $\begin{array}{c}\text { Cell body } \\
\text { diameter }(\mu \mathrm{m})\end{array}$ & N \\
\hline $\mathrm{M}$ & TDV & $0-1$ & $29 \pm 13$ & $8.6 \pm 1.2$ & 6 \\
$\mathrm{M}$ & TDV & 7 & $257 \pm 35$ & $16 \pm 2$ & 5 \\
& Nasal & $0-1$ & $19 \pm 4$ & $7.7 \pm 1$ & 21 \\
$\mathrm{P}$ & Nasal & 8 & $174 \pm 30$ & $14 \pm 1$ & 13 \\
& TDV & $0-1$ & $9.8 \pm 3.2$ & $7.5 \pm 1$ & 124 \\
$\mathrm{P}$ & TDV & 6 & $96 \pm 21$ & $11 \pm 1$ & 6 \\
& Nasal & $0-1$ & $7 \pm 1.9$ & $7.6 \pm 1$ & 58 \\
& Nasal & 8 & $55 \pm 5$ & $10 \pm 1$ & 7 \\
\hline
\end{tabular}

Measurements were performed on well-stained cells from the retinas of all 4 animals used in the study. Data are reported as means \pm SD. TDV $=$ temporal, dorsal, and ventral quadrants.

Table 2. $M$ and $P$ cell mosaics labeled from Biocytin deposits in the optic nerve, indicating the distance from the fovea, and number of cells retrogradely labeled in a 1$\mathrm{mm}^{2}$ area.

\begin{tabular}{|c|c|c|c|c|c|c|}
\hline Cell class & Location & $\begin{array}{l}\text { Eccentricity } \\
(\mathrm{mm})\end{array}$ & $\begin{array}{c}\text { Cell } \\
\text { count }\end{array}$ & $r(\mu \mathrm{m})$ & $\begin{array}{l}\text { Packing } \\
\text { factor }\end{array}$ & $\begin{array}{l}\text { Cell density } \\
\text { (cells } / \mathrm{mm}^{2} \text { ) }\end{array}$ \\
\hline M outer & Temporal & 2.5 & 165 & 37 & 0.50 & 429 \\
\hline$M$ inner & Temporal & 2.3 & 120 & 50 & 0.66 & 309 \\
\hline M outer & Ventral & 4.7 & 58 & 62 & 0.58 & 176 \\
\hline M inner & Ventral & 4.5 & 58 & 47 & 0.56 & 288 \\
\hline M outer & Ventral & 6.7 & 31 & 94 & 0.64 & 83 \\
\hline M inner & Ventral & 7.0 & 30 & 96 & 0.70 & 88 \\
\hline M outer & Nasal & 4.5 & 98 & 41 & 0.57 & 388 \\
\hline$M$ inner & Nasal & 4.9 & 66 & 65 & 0.57 & 156 \\
\hline M outer & Nasal & 6.7 & 85 & 56 & 0.55 & 198 \\
\hline$M$ inner & Nasal & 6.8 & 80 & 59 & 0.67 & 220 \\
\hline M outer & Nasal & 8.8 & 66 & 80 & 0.56 & 101 \\
\hline M inner & Nasal & 8.7 & 64 & 73 & 0.54 & 117 \\
\hline P outer & Temporal & 2.5 & 632 & 9 & 0.27 & 3818 \\
\hline $\mathrm{P}$ inner & Temporal & 2.3 & 529 & 18 & 0.48 & 1719 \\
\hline P outer & Ventral & 4.0 & 388 & 20 & 0.72 & 2041 \\
\hline$P$ inner & Temporal & 5.0 & 195 & 12 & 0.25 & 1965 \\
\hline P outer & Ventral & 5.9 & 208 & 22 & 0.47 & 1148 \\
\hline$P$ inner & Ventral & 6.8 & 131 & 41 & 0.67 & 465 \\
\hline P outer & Nasal & 3.9 & 316 & 16 & 0.43 & 1895 \\
\hline$P$ inner & Nasal & 4.0 & 186 & 17 & 0.48 & 1823 \\
\hline P outer & Nasal & 6.5 & 208 & 31 & 0.65 & 761 \\
\hline$P$ inner & Nasal & 6.9 & 166 & 33 & 0.58 & 600 \\
\hline P outer & Nasal & 9.0 & 82 & 61 & 0.59 & 182 \\
\hline$P$ inner & Nasal & 8.8 & 83 & 50 & 0.65 & 297 \\
\hline
\end{tabular}

All mosaics were obtained from the same retina to avoid interindividual variability. The effective radius ( $r$ ), packing factor, and cell density of the final interpolated mosaic obtained by statistical analysis are also presented. 
Figure 4. A, Marmoset outer $\mathrm{M}$ cell mosaic, located $2.5 \mathrm{~mm}$ temporal to the fovea, labeled by Biocytin retrograde transport. In primates, ganglion cell retrograde labeling from Biocytin deposits in the optic nerve stains only a fraction of cells belonging to a given mosaic. Only the cell bodies and primary dendrites were drawn. $B$, The same mosaic illustrated in $A$, showing both the labeled cells (filled circles) and the interpolated cells (open circles). The latter were placed using the spatial statistical analysis described in the text. For the analysis zone, delimited by the central square, we estimated a cell density of 376 outer $\mathrm{M}$ cells $/ \mathrm{mm}^{2}$. Scale bar $=250 \mu \mathrm{m}$.

Figure 5. A, Marmoset outer $\mathrm{P}$ cell mosaic, located $6.5 \mathrm{~mm}$ nasal to the fovea, labeled by Biocytin retrograde transport. Only the cell bodies and primary dendrites were drawn. $B$, The same mosaic illustrated in $A$, showing both the labeled cells (filled circles) and the interpolated cells (open circles). The latter were placed using the spatial statistical analysis described in the text. For the analysis zone, delimited by the central square, we estimated a cell density of 761 outer $P$ cells $/ \mathrm{mm}^{2}$. Scale bar $=250 \mu \mathrm{m}$.

Figure 6. $\mathrm{M}$ and $\mathrm{P}$ ganglion cell density as a function of retinal eccentricity in the marmoset retina. Cell density was estimated by spatial statistical analysis of Biocytin retrogradely labeled mosaics as described in the text. $A, M$ ganglion cell density. $B, P$ ganglion cell density. Values for the outer and inner varieties of $M$ and $P$ cells were plotted separately. Total cell density for $M$ and $P$ cells was obtained by adding the values for the inner and outer varieties and plotting them in the mean eccentricity for the two mosaics. The density of both $\mathrm{M}$ and $\mathrm{P}$ cells increased towards the fovea. The M cell density was higher in the nasal quadrant than in the temporal, dorsal, and ventral (TDV) quadrants for similar eccentricities.
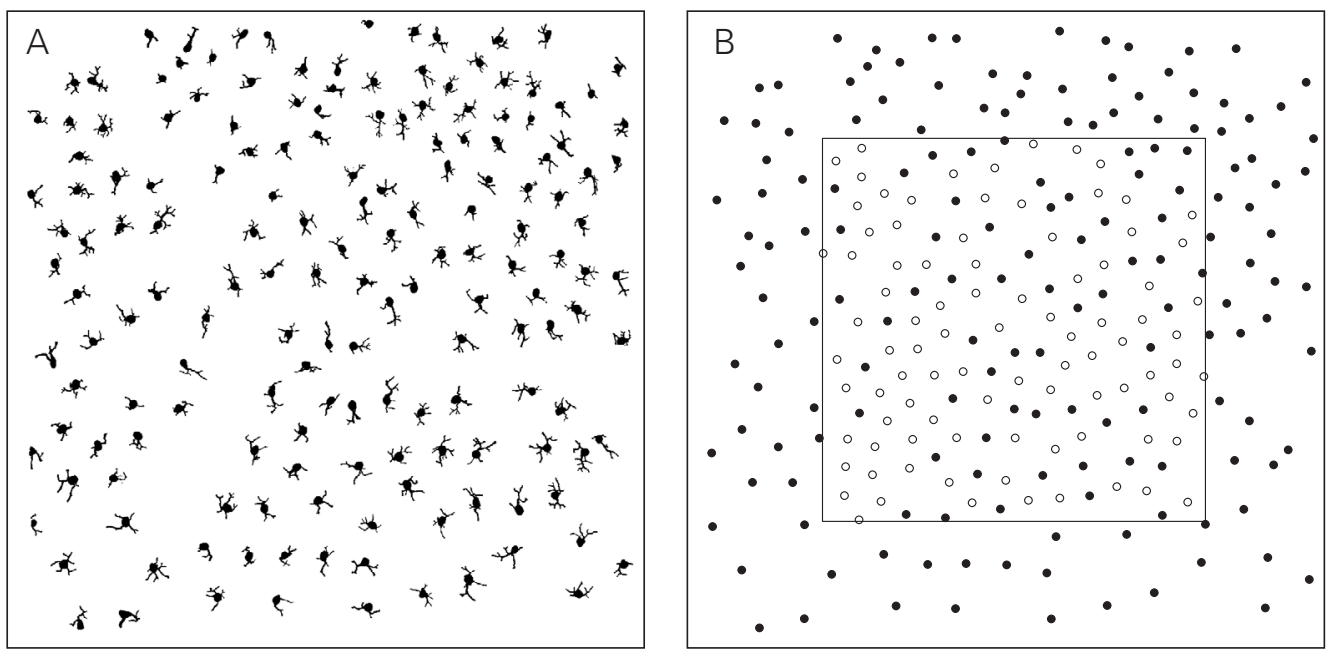
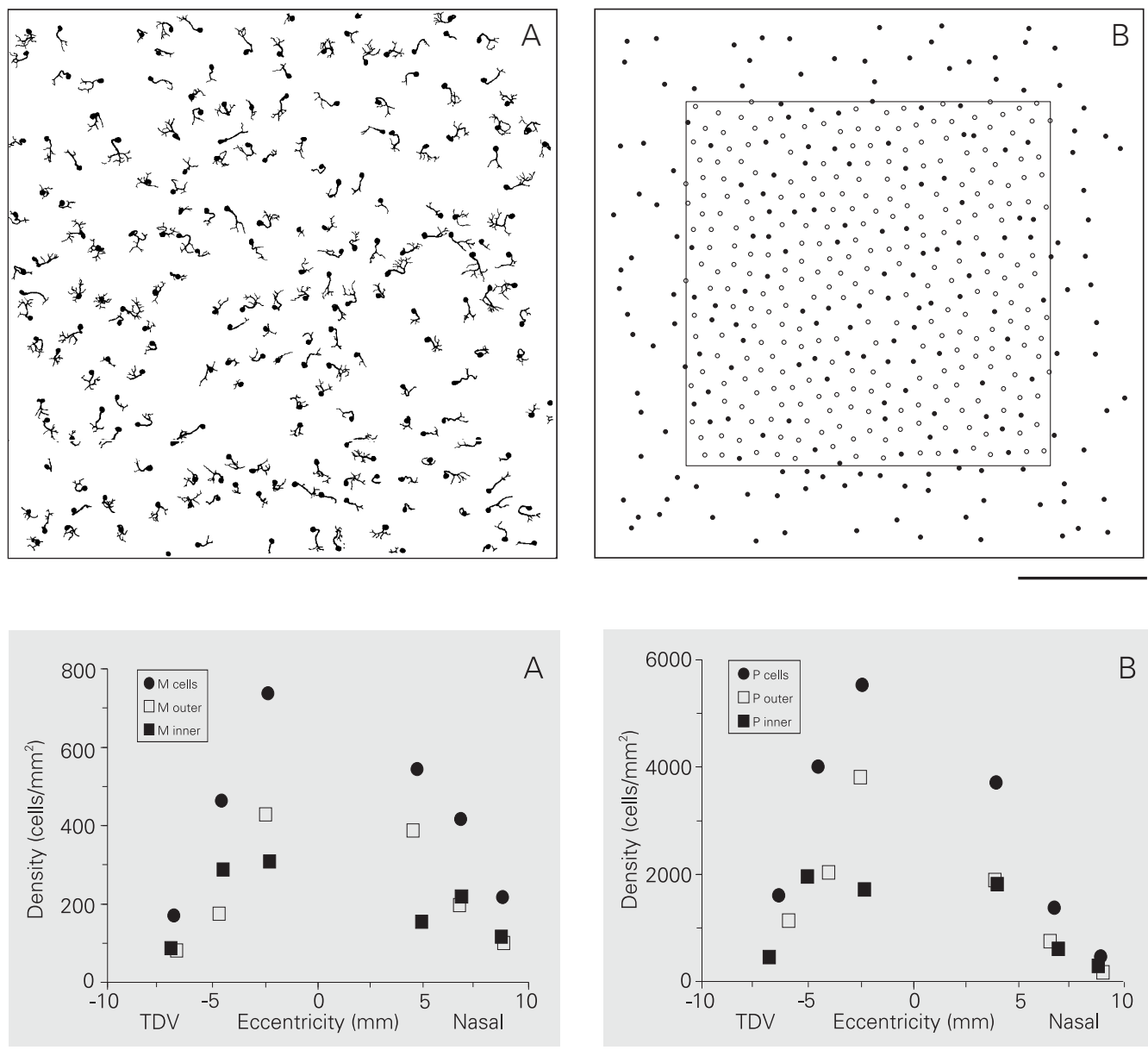
scribed in the Material and Methods section. The total cell density for $\mathrm{M}$ and $\mathrm{P}$ cells was then obtained by adding the values for the inner and outer varieties and plotting them against the mean eccentricity for the two mosaics (Figure 6). Both $\mathrm{M}$ and $\mathrm{P}$ cell densities decreased with eccentricity in the marmoset retina, and the decrease was steeper in the TDV quadrants than in the nasal quadrant, especially for $\mathrm{M}$ cells. We estimated $\mathrm{M}$ and $\mathrm{P}$ cell density using mosaics at increasing distances from the fovea in the intermediate and peripheral retinal regions (2.5-9 $\mathrm{mm}$ of eccentricity). It was not possible to use the same method for the foveal slope due to the multilayered structure of the ganglion cell layer in this region. $\mathrm{M}$ cell density decreased towards the retinal periphery in all quadrants. M cell density was higher in the nasal quadrant than in other retinal regions at similar eccentricities, reaching about 740 cells $/ \mathrm{mm}^{2}$ at $2.5 \mathrm{~mm}$ of temporal eccentricity. $\mathrm{P}$ cell density increased from peripheral to more central retinal regions, reaching about $5540 \mathrm{cells} / \mathrm{mm}^{2}$ at 2.5 $\mathrm{mm}$ of temporal eccentricity.

\section{Proportion of $\mathrm{M}$ and $\mathrm{P}$ cells in the total ganglion cell population}

We compared the $\mathrm{M}$ and $\mathrm{P}$ cell density values obtained in the present study with the values published by Wilder et al. (3) for total ganglion cell density in the marmoset (Figure 7). In Figure 8, we replotted the data reported by Wilder et al. (3) for each retina and their mean total ganglion cell density, as well as our estimates for $\mathrm{M}$ and $\mathrm{P}$ cell density. In the range of eccentricities studied here $(2.5-9 \mathrm{~mm}$ from the fovea), $\mathrm{M}$ cells represent $8-14 \%$ of all ganglion cells, while $\mathrm{P}$ cells represent $20-50 \%$ in the nasal quadrant and a larger proportion of all ganglion cells in the other quadrants, exceeding $80 \%$ in some locations. Also, all quadrants tended to show an increase in the proportion of $\mathrm{P}$ cells towards central retinal regions. In the present study, the $\mathrm{M}$ and $\mathrm{P}$ proportions were estimated using the mean total ganglion cell density reported by Wilder et al. (3). However, since there is a wide variation in ganglion cell density from animal to animal (see Figure 8), the exact proportion for each ganglion cell class should be estimated ideally from $\mathrm{M}, \mathrm{P}$, and total ganglion cell densities measured in the same retina.

Having the density values for $\mathrm{M}$ and $\mathrm{P}$ cells, we were able to calculate the $\mathrm{P} / \mathrm{M}$ density ratio for different regions of the marmoset retina. In the nasal quadrant, the $\mathrm{P} / \mathrm{M}$ density ratio decreased from 7 in central locations to 2 in the retinal periphery, but in other quadrants it remained between 9 and 8 .

\section{Dendritic coverage factor of $M$ and $P$ cells}

We used the measurements of dendritic field size and cell density to estimate the coverage factor for the inner and outer varieties of $\mathrm{M}$ and $\mathrm{P}$ cells and then to combine

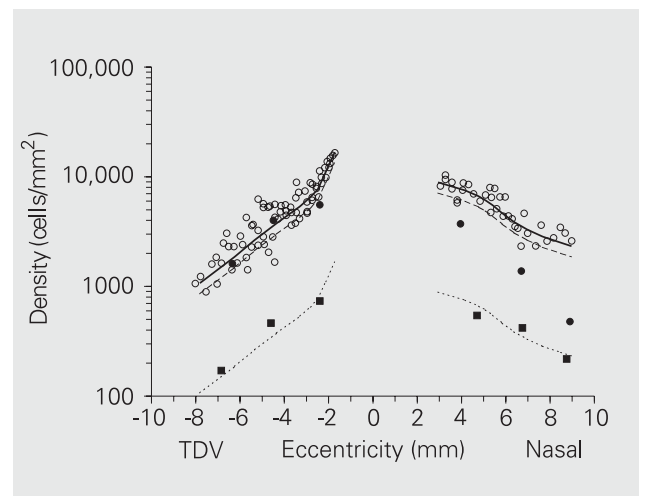

Figure 7. Comparison between total ganglion cell density (individual values for different animals, replotted from Wilder et al. (3) (open circles) and predicted $M$ and $\mathrm{P}$ cell density from the present study as a function of eccentricity in the marmoset retina. The solid line represents the mean values for total ganglion cell density reported by Wilder et al. (3). Traced and dotted lines represent 80 and $10 \%$ of the mean total ganglion cell density, respectively. $M$ (filled squares) and $P$ cell (filled circles) density values were replotted from Figure 6. There is an increase in $\mathrm{M}$ and $\mathrm{P}$ cell density from the periphery towards more central regions. $M$ cell density was about $10 \%$ in all retinal locations studied. $\mathrm{P}$ cell density was about $80 \%$ in all quadrants except the nasal quadrant where it decreased to $20-50 \%$. TDV = temporal, dorsal, and ventral quadrants. 
the results obtained for each subpopulation to estimate the total $\mathrm{M}$ and $\mathrm{P}$ cell coverage factor at different retinal locations (Figure 8 ). We found that $\mathrm{M}$ and $\mathrm{P}$ cell coverage varies substantially throughout the marmoset retina. The $\mathrm{M}$ cell coverage factor ranged from 5 to 12 . The $\mathrm{P}$ cell coverage factor ranged from 1 to 3 in the nasal quadrant and from 5 to 12 in the other quadrants.

\section{Regularity of $\mathrm{M}$ and $\mathrm{P}$ cell mosaics}

The regularity of $\mathrm{M}$ and $\mathrm{P}$ cell mosaics in the marmoset retina after cell interpolation was calculated using the regularity index (14) and packing factor (13). The regularity index, also called conformity ratio (15), was obtained by estimating the ratio between mean nearest neighbor distance and its standard deviation. Theoretically, a random population has a mean regularity index of 1.913 (15). Mosaics with a high degree of regularity have small standard deviations and, consequently, a high-regularity index (14). The

Figure 8. A, Coverage factor for marmoset $M$ cells at different distances from the fovea. $B$ Coverage factor for marmoset $P$ cells at different distances from the fovea. The coverage factor was calculated using the dendritic field and density measurements for the inner and outer varieties of each cell class. The sum of values for the inner and outer varieties expresses the total coverage for $\mathrm{M}$ and $\mathrm{P}$ cells. The $M$ cell coverage is larger than the $\mathrm{P}$ cell coverage in the nasal quadrant, but similar in the temporal, dorsal, and ventral (TDV) quadrants.

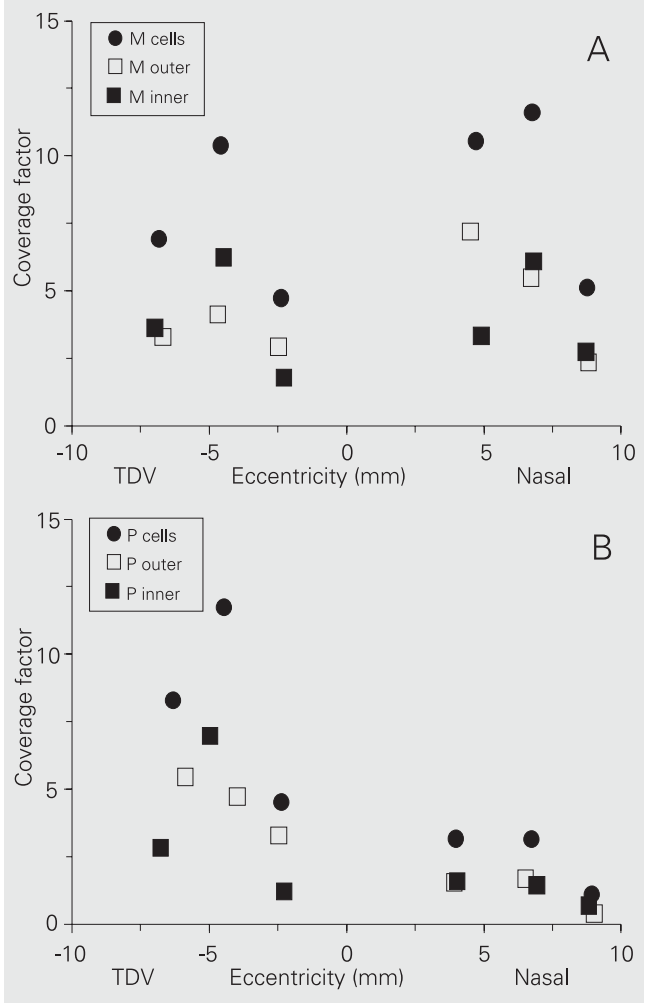

packing factor is an adimensional measurement of how packed mosaic elements are arranged which ranges from 0 to 1 . A crystalline hexagonal mosaic has a packing factor of 1 , while random mosaics have lower values near 0 (13). The regularity index ranged from 6 to 35 and from 9 to 50 for $\mathrm{M}$ and $\mathrm{P}$ cells, respectively. The packing factor ranged from 0.5 to 0.7 and from 0.25 to 0.72 for $\mathrm{M}$ and $\mathrm{P}$ cells, respectively (Table 2 ). Although the packing factor is a measure of packing, not of regularity, a large packing factor implies some degree of regularity (13). Thus, the packing factor values obtained for the majority of mosaics in the present study indicate that the mosaics have a fair degree of regularity.

\section{Discussion}

Retrograde labeling with Biocytin: a good method to study the morphology and distribution of $M$ and $P$ cells

Marmoset $\mathrm{M}$ and $\mathrm{P}$ cells retrogradely labeled with Biocytin were morphologically similar to those labeled by in vivo intracellular injection of Neurobiotin or by DiI transport in fixed tissue $(17,19)$. Differently from previous studies on marmoset retina (17), we had the advantage of obtaining many well-labeled cells in central retina, very close to the fovea. Thus, a more complete picture about how cell body and dendritic field sizes vary with distance from the fovea was achieved using Biocytin retrograde labeling. For each cell studied we were able to resolve cell body, dendrites and axon, as well as the level of dendritic stratification in the inner plexiform layer.

No differences were seen in the dendritic field sizes of the inner and outer varieties of marmoset $\mathrm{M}$ and $\mathrm{P}$ cells. This finding conflicts with the data of Ghosh et al. (17) for the same animal, which show that the inner dendritic trees are larger than the outer ones. Careful inspection of Figure 2 reveals that in 
some regions this might be the case but the opposite is also observed in other retinal eccentricities. The average difference for $\mathrm{M}$ cell dendritic field diameter reported by Ghosh et al. (17) was only 7\%. This small difference can be easily obscured by pooling cells from different locations and different animals as we did in the present study.

\section{Proportion of different cell classes throughout the marmoset retina}

By means of spatial statistical methods we could calculate cell density, regularity, and coverage of $\mathrm{M}$ and $\mathrm{P}$ cell mosaics in different locations of the midperipheral and peripheral retina. Perry et al. (4) estimated that $\mathrm{M}$ cells, $\mathrm{P}$ cells, and other cell classes represented 10,80 , and $10 \%$ of all ganglion cells in the macaque retina, respectively. Silveira and Perry (8), Lima et al. (9) and Yamada et al. (7) found $\mathrm{M}$ cells to represent up to $20 \%$ of the total of ganglion cells in some regions of the capuchin and owl-monkey retinae. Using our results for $\mathrm{M}$ and $\mathrm{P}$ cell density and those of Wilder et al. (3) for the density of all ganglion cells, we could estimate how the proportion of different cell classes changes with eccentricity in the marmoset retina. In the temporal, dorsal, and ventral quadrants, the 1:8:1 proportion for $\mathrm{M}, \mathrm{P}$, and other ganglion cell classes seems to hold for the marmoset retina. In these retinal regions there was a good correlation between the predicted values for $\mathrm{M}$ and $\mathrm{P}$ cell proportions, such as 10 and $80 \%$ of total ganglion cell density estimated by Wilder et al. (3), and our results (Figure 7). However, in the nasal quadrant, the $\mathrm{P}$ cell proportion decreased and was accompanied by a slight increase in the proportion of $\mathrm{M}$ cells and other ganglion cell classes (Figure 7).

\section{Dendritic coverage of $M$ and $P$ cells in the marmoset retina}

There are only a few reports in the litera- ture about $\mathrm{M}$ and $\mathrm{P}$ cell dendritic coverage (man: $(5,6)$; macaque monkey: $(1,4)$; capuchin monkey: (7); common marmoset: (17)). In the marmoset retina, Ghosh et al. (17) estimated a coverage factor above 4 for 16 pairs of M cells located between 4.5 and 5.5 $\mathrm{mm}$ in the nasal retina. In the present study, we found that the $\mathrm{M}$ cell coverage factor ranged from 4.8 to 11.6 for different retinal locations (Figure 7). For another platyrrhine species, the capuchin monkey, Yamada et al. (7) also showed that $\mathrm{M}$ and $\mathrm{P}$ cell coverage factor changes with eccentricity, between 26.3 and 1.4-3.4, respectively, for different locations in the nasal and temporal retina. The numerical differences in the $\mathrm{M}$ and $\mathrm{P}$ cell coverage factor between capuchin monkeys and marmosets may be a species difference or may be related to the different methods used in the two studies.

\section{Limitations imposed by the mosaics of $M$ and $P$ cells on the visual acuity of marmosets}

Retinal ganglion cell density limits visual acuity, especially at the retinal periphery, where there is a high cone convergence onto ganglion cells. Near the fovea, the main factor that determines the limit of spatial resolution is cone density and packing (20, 21). Troilo et al. (22) calculated the Nyquist frequency imposed by photoreceptors in central and nasal regions of the marmoset retina. In the foveal region, the Nyquist frequency was 30 cycles/degree for marmosets (22), as opposed to 66 cycles/degree for humans (23). In the retinal periphery, the Nyquist frequency was estimated using the total ganglion cell density, and was found to be 3 cycles/degree for both humans and marmosets $(3,22)$.

We estimated the Nyquist frequency for marmoset $\mathrm{M}$ and $\mathrm{P}$ cells at different retinal locations. In TDV regions, the Nyquist frequency for P cells changed from 5.2 cycles/ degree at $2.4 \mathrm{~mm}\left(19.4^{\circ}\right)$ to 2.5 cycles/degree at $6.4 \mathrm{~mm}\left(50.8^{\circ}\right)$. The Nyquist fre- 
quency for $\mathrm{M}$ cells was 1.9 cycles/degree at $2.4 \mathrm{~mm}\left(19.4^{\circ}\right)$ and 0.8 cycles/degree at 6.9 $\mathrm{mm}\left(55.5^{\circ}\right)$. In the nasal region, this value was 4.2 cycles/degree at $4 \mathrm{~mm}\left(31.2^{\circ}\right)$ and 1 cycle/degree at $8.9 \mathrm{~mm}\left(78^{\circ}\right)$ for $\mathrm{P}$ cells and 1.6 cycles/degree at $4.7 \mathrm{~mm}\left(37^{\circ}\right)$ and 0.8 cycles/degree at $8.8 \mathrm{~mm}\left(76^{\circ}\right)$ for $\mathrm{M}$ cells. These values are compatible with the proposed roles of both cell classes in spatial vision. $\mathrm{P}$ cells might be important for high spatial frequency detection because they are the only ganglion cell class that sees at this end of the spatial frequency spectrum. However, $M$ cells are also important in intermediate and low spatial frequencies due to their superior sensitivity to low contrast. In the range of spatial frequency in which both cell classes are sensitive, the combination of their signals at the level of the primary visual cortex should provide the amount of information required for animal visual performance (24).

\section{Acknowledgments}

We thank Dr. José Augusto Pereira Carneiro Muniz, head of the Centro Nacional de Primatas, for providing the monkeys used in this study.

\section{References}

1. Perry VH \& Cowey A (1985). The ganglion cell and cone distributions in the monkey's retina: implication for the central magnification factors. Vision Research, 25: 1125-1137.

2. Silveira LCL, Picanço-Diniz CW, Sampaio LES \& Oswaldo-Cruz EO (1989). Retinal ganglion cell distribution in the Cebus monkey: a comparison with the cortical magnification factor. Vision Research, 29: 1471-1483.

3. Wilder HD, Grünert U, Lee BB \& Martin PR (1996). Topography of ganglion cells and photoreceptors in the retina of a New World monkey: the marmoset Callithrix jacchus. Visual Neuroscience, 13: 335-352.

4. Perry VH, Oehler R \& Cowey A (1984). Retinal ganglion cells that project to the dorsal lateral geniculate nucleus in the macaque monkey. Neuroscience, 12: 1101-1123.

5. Dacey MD \& Petersen MR (1992). Dendritic field size and morphology of midget and parasol ganglion cells of the human retina. Proceedings of the National Academy of Sciences, USA, 89: 96669670.

6. Dacey DM (1993). The mosaic of midget ganglion cells in the human retina. Journal of Neuroscience, 13: 5334-5355.

7. Yamada ES, Silveira LCL \& Perry VH (1996). Morphology, dendritic field size, somal size, density and coverage of $M$ and $P$ retinal ganglion cells of dichromatic Cebus monkeys. Visual Neuroscience, 13: 1011-1029.

8. Silveira LCL \& Perry VH (1991). The topography of magnocellular projecting ganglion cells (M-ganglion cells) in the primate retina. Neuroscience, 40: 217-237.

9. Lima SMA, Silveira LCL \& Perry VH (1996). Distribution of the M retinal ganglion cells in diurnal and nocturnal New World monkeys. Journal of Comparative Neurology, 368: 538-552.

10. Gomes FL, Yamada ES, Silveira LCL, Lee BB \& Muniz JAP (1997). Density and dendritic field size of $M$ and $P$ retinal ganglion cells of dichromatic marmosets. Investigative Ophthalmology and Visual Science, 38: S50 (Abstract).

11. Picanço-Diniz CW, Silveira LCL, Yamada ES \& Martin KAC (1992). Biocytin as a retrograde tracer in mammal visual system. Brazilian Journal of Medical and Biological Research, 25: 57-62.

12. Shu SM, Raine L \& Fagner H (1981). Use of avidin-biotin peroxidase complex $(\mathrm{ABC})$ in immunoperoxidase techniques. Journal of Histochemistry and Cytochemistry, 29: 577-580.

13. Rodieck RW (1991). The density recovery profile: A method for analysis of points in the plane applicable to retinal studies. Visual Neuroscience, 6: 95-111.

14. Wässle H \& Riemann HJ (1978). The mosaic of nerve cells in the mammalian retina. Proceedings of the Royal Society of London. Series B, Biological Sciences, 200: 441-461.

15. Cook JE (1996). Spatial properties of retinal mosaics: an empirical evaluation of some existing measures. Visual Neuroscience, 13: 1530.

16. Silveira LCL, Yamada ES, Perry VH \& Picanço-Diniz CW (1994). M and $P$ retinal ganglion cells of diurnal and nocturnal New World monkeys. NeuroReport, 5: 2077-2081.

17. Ghosh KK, Goodchild AK, Sefton AE \& Martin PR (1996). The morphology of retinal ganglion cells in the New World marmoset monkey Callithrix jacchus. Journal of Comparative Neurology, 366: 76-92.

18. Polyak SL (1941). The Retina. University of Chicago Press, Chicago, IL, USA.

19. Yamada ES, Silveira LCL, Gomes FL \& Lee BB (1996). The retinal ganglion cell classes of New World primates. Revista Brasileira de Biologia, 56 (Suppl 1): 381-396.

20. Hirsch J \& Hylton R (1984). Quality of the primate photoreceptor lattice and limits of spatial vision. Vision Research, 24: 347-355.

21. Snyder AW \& Miller WH (1977). Photoreceptor diameter and spacing for highest resolving power. Journal of the Optical Society of America, 67: 696-698.

22. Troilo D, Howland HC \& Judge SJ (1993). Visual optics and retinal cone topography in the common marmoset (Callithrix jacchus). Vision Research, 33: 1301-1310.

23. Curcio CA, Sloan KL, Kalina RE \& Hendrickson AE (1990). Human photoreceptor topography. Journal of Comparative Neurology, 292: 497-523.

24. Silveira LCL \& de Mello Jr HD (1998). Parallel pathways of the primate vision: sampling of the information in the Fourier space by $\mathrm{M}$ and $\mathrm{P}$ cells. In: Chalupa LM \& Finlay BL (Editors), Development and Organization of the Retina: From Molecules to Function. Plenum Press, New York. 